\title{
Managerial Levels and Translation Issues: The Case of the Italian Quadri
}

\author{
Pietro Manzella \\ Association for International and Comparative Studies in the field of Labour Law and \\ Industrial Relations (ADAPT) \\ Via Garibaldi 7, 24122 Bergamo, Italy
}

Tel: 3932-9388-1878Ｅ-mail: pietro.manzella@adapt.it

Received: July 24, 2019 Accepted: September 18, 2019 Published: November 6, 2019

doi:10.5296/ijl.v11i6.15143

URL: https://doi.org/10.5296/ijl.v11i6.15143

\begin{abstract}
This paper is concerned with the translation issues resulting from attempts to render in other languages the terminology denoting the national systems of employment classification. To this end, the Italian notion of quadri was investigated, and the ways it was translated into English in a dataset consisting of annual reports produced in both languages.
\end{abstract}

Keywords: Translation, Employee relations, English, Italian, Job classification

\section{Introduction}

The complex interplay between translation and multinational management has been investigated at length and from different research angles. Companies operating outside national borders set much store by linguistic issues, to the extent that some of them "have permanent translators on staff to manage such issues as interaction with the international press, the translation of local product information, and negotiation with other companies" (Cullen and Parboteeath, 2013, p. 569). Therefore, the terminology question comes to the fore, as language permeates multinational operations in a number of ways. It is a given that English is used as lingua franca in international business, both in commercial activities and in relation with overseas branches (Fairbrother, 2018). Nevertheless, some documents need to be produced both in English and in the language of the country where the company is headquartered. This is the case of annual reports, which summarise the most relevant financial information and, as such, must be drafted and translated carefully. Publishing reporting specifics in both English and the language of the country where the company is incorporated also enables external users to access this type of information (Erkens, 2016). As 
far as translation is concerned, one section of the annual reports that is particularly tricky is that concerning labour costs, where the expenses resulting from employing labour are usually detailed. Labour terminology might pose translation challenges in that some concepts can be nation-specific, thus adding a further hurdle at the time of engaging in comparative analysis (Manzella, 2017). The struggle stemming from rendering words pertaining to labour discourse can be illustrated by looking at the terms employed to refer to managerial roles, as the terminology used in a country might not have an exact equivalent in other national contexts. In view of the above, the present research will consider the language used to refer to managerial levels in company reports, examining the strategies put forward by translators to render them in different languages. To this end, the English and Italian version of annual reports drafted by multinationals headquartered in Italy and listed on Borsa Italiana will be investigated. The research focus will be on the notion of quadri, a managerial role that is singular to the Italian system, supplying a critical evaluation of the expressions used in English to translate it. The raison d'être for researching into the notion of quadri is that this terminology has been given little attention in Translation Studies (TS), although it lends itself to some interesting considerations from a linguistic and conceptual standpoint. These introductory remarks will be followed by an examination of existing literature, which, besides TS, will need to consider necessarily the domain of multinational management and employee relations (Section 2). Next comes an overview of the methodology employed to carry out research and some definitional aspects (Section 3), along with data analysis (Section 4). Finally, some concluding remarks will be supplied (Section 5), pointing out the limitations of this analysis and putting forward some suggestions for future research.

\section{Theoretical Background}

As referred to in the previous paragraph, the translation of managerial levels has attracted little interest on the part of TS scholarship (Khuddro, 2016; Tietze, 2013). Pierini and Tosi (2006) have posited that the terminology employed to translate managerial levels from English into Italian can be misleading, as a result of the translation process itself. An interesting approach as far as the linkages between translation and culture are concerned is the one put forward by Bargiela-Chiappini (2001). She speaks of a genuine "titles war" waged by Italian companies. In this sense the new denominations of Italy's managerial levels, which are often in English, fail to capture the duties fulfilled by Italian middle managers, as well as to match the expectations of the British management working with its Italian counterpart (Bargiela-Chiappini, 2001). This view has been reinforced by Tietze (2013), who has argued that the role of English in job descriptions does not contribute to furthering collaborative relations, but experienced by the thus re-labelled Italian middle managers as devoid of meaning and substance (Tietze, 2013). Examining the discourse of corporate meetings, Bargiela-Chiappini and Harris (1997) have noted that a number of discrepancies exist between the British managerial levels (low, middle, and senior) and the Italian quadri and dirigenti. This point has sparked lively debate about the assumed semantic comparability of notions and practices on a cross-national level (Bargiela-Chiappini and Harris, 1997).

Cross-cultural and international management research has also considered the issue at length. Discussing the rendering of the French dirigeant, Lorriman has argued that this terminology 
has no direct equivalent in English, because its meaning could include CEOs, executives, top executives, the executive, and this list is far from exhaustive (Lorrimar, 2010). The author points out that another French term that lends itself to many interpretations is cadre, which can be translated into English as "middle manager", "manager", and "executive" (Lorrimar, 2010). This point is also made by Barsoux and Lawrence (2006) who maintains that the term cadre has no equivalent in other languages; it basically corresponds to "manager" in English, though with rather different legal and sociological connotations.

Finally, scholars in comparative employee relations too have investigated the difficulties resulting from rendering managerial roles in a number of languages. Hyman has stressed that there is no real English term for cadre or prud'homme, for the structuring of the technical-managerial workforce, and the adjudication of employment grievances, follow very different lines in Britain from those in France (Hyman, 2005). Similarly, Tiraboschi points out that an analysis of collective bargaining and business practice clearly shows that the vague notion of "executive staff" encompasses at least two groups of employees governed by divergent legal and contractual provisions: top managers (dirigenti) on the one hand, and middle management (quadri or quadri intermedi) on the other hand (Tiraboschi, 2010).

\section{Definitional and Methodological Aspects}

Defining the notion that will be looked at is an important stage when engaging in comparative analysis. Appreciation of the meaning of the concept under scrutiny helps one to understand if the terminology used in the target language and system is appropriate to convey its significance. In other words, definitions help us to establish likeness being aware of difference (Hyman, 2005). The first aspect that needs pointing out is that in the current paper we will discuss the terminological differences arising from the translation of job and managerial levels, with the latter referring to "the location of the job in the formal hierarchy of authority" (Mintzberg, 2009, p. 109). Looking at quadri, which is the concept that will be investigated in this paper, it is concerned with the vague category of "executive staff" - in which top managers and cadres are also included - and are defined as middle managers. In other words, quadri consist of highly qualified professionals who perform functions of considerable significance within the undertaking. They are a restricted category of workers, in between white-collar workers and top-level managers strictly speaking, characterized by a specific professional status and by their level of responsibility, power and autonomy (Tiraboschi, 2010). One problem in relation to this definition of quadri is that:

The degeneration of the concept of top-level manager (dirigente), that has been extended to include roles quite distinct from the traditional concept of a manager as the employer's alter ego, has ended up watering down the concept of middle management or cadre (quadro or quadro intermedio), which now differs only slightly from that of white-collar employee (impiegato) (Tiraboschi, 2010, p. 2).

Consequently, even the definition of quadri as middle managers can be questioned. This is also due to the fact that in Italy, middle management can comprise at least two different managerial levels, namely "managers" strictly speaking and "professionals". Managers are highly qualified workers with responsibility for staff and programmes; they oversee production and other employees, carrying out managerial functions. Professionals are highly 
qualified workers who are not necessarily in charge of staff or programmes. In this sense, the Italian quadri falls within this second category. As shall we see further on in this paper, the terminological problem marking the notion of quadri will also affect its translation into English.

In terms of methodology, this research will consider a dataset consisting of annual reports produced in Italian and then translated into English. The analysis will focus on the documents produced by a selected number of companies listed on Borsa Italiana. As of December 2018, 357 companies have their share quoted on Italy's Stock Market Exchange (Borsa Italiana, 2018). Of them, only those with following characteristics were considered for the purpose of this research:

- they included a section about personnel costs in their reports;

- they provide a classification of their managerial levels in their reports;

- the word quadri appears in the Italian version of their annual reports.

Consequently, 250 out of the 357 companies referred to above were included in the dataset investigated in this research. The analysis will look at the ways quadri was translated into the English versions of the report, to see if the terminology provided in the target language deviate from, or fully convey, the meaning of the notion in the source system.

\section{Finding Analysis}

In the English texts investigated, it emerges that the following terminology was used to refer to the Italian quadri:

Table 1. Terminology used in corporate reports to translate quadri into English

\begin{tabular}{ll}
\hline Terminology & Occurrence \\
\hline Middle Managers & 144 \\
\hline Managers & 57 \\
\hline Supervisors & 35 \\
\hline Senior Managers & 14 \\
\hline
\end{tabular}

Source: Author's Own Elaboration (2019)

We will now have a look at all these expressions to see if they do justice to the meaning in the source language.

\subsection{Middle Managers}

"Middle managers" is by far the most widespread wording employed in the English version of the texts examined to convey the meaning of quadri. Even though they are part of the broad category of executive staff - which also includes top management - as seen in the Italian context middle management are referred to as "highly qualified professionals who perform functions of considerable significance within the undertaking" (Tiraboschi, 2010, p. 
7). They are a category in between white-collar workers and top-level managers, featuring a specific level of responsibility, power and autonomy (Tiraboschi, 2010). For the purposes of comparison, "middle managers" might thus be a good rendering of the Italian quadri. Nevertheless, as already stressed in the definitional section, the expression "middle managers" encompasses two different professional profiles, namely "managers" and "professionals". The two functions are different not only in terms of tasks, but also in terms of variables such as age, seniority in the company, professional experience, and qualifications, with the latter which seems to better convey the meaning of quadri. "Middle managers" might thus be regarded as a superordinate, in that it is an umbrella term employed to refer to two managerial functions, that is managers strictly speaking and professionals (Italy's quadri). Evidently, generalization (or generalizing) is a widespread strategy in translation. As recalled by Byrne, resorting to this approach might be useful - when the target language does not have a similarly specialized term - or even necessary when source text terminology is too a specific one (Byrne, 2012). However, using a catch-all term is possible only when understanding of original information is not affected. Consequently, the wording "middle managers" is a suitable one to translate quadri into English. Nevertheless, and whereas possible, this expression should be avoided, as it might give rise to confusion as to which function (i.e. professionals or managers) quadri corresponds.

\subsection{Managers}

"Managers" is another word that is frequently employed in the annual reports scrutinized to translate quadri into English. This choice might be challenged for at least two reasons. Firstly, this word is too a general one, as managers are a notoriously difficult group to define. As pointed out by Stoley, Edwards and Sisson, attempts to supply a definition of a manager have provoked lengthy and often inconclusive debate (Storey, Edwards and Sisson, 1997), up to the point that those who have engaged in this exercise have been seen as trying to define the undefinable. In general terms, managers can be regarded as certain people or occupations within an organization who have specific responsibilities for "managing" activities, which are likely to include organizing or managing the work of other people (Preece, Steven and Steven, 1999). The general character of this word makes it difficult to identify the roles managers perform, thus using this terminology to refer to quadri might be misleading. Secondly, and more related to the Italian context, we have seen in 4.1. that the notion of a manager is distinct from that of a professional, with the latter that fully captures the task performed by quadri. While they are both seen as subcategories of executive staff members, these two categories of employee perform wholly different functions. Making use of "managers" to translate quadri might bewilder the international reader, who might wrongly imply that the latter perform tasks they actually do not. For this reason, it is advisable to use proper terminology in the target text to refer to managerial functions, in order to prevent misinterpretations and misunderstandings. The issues just discussed brings to mind the arguments by Brewster, Tregaskis, Hegewisch and Mayne (2003) who posit that, rather than translation effectiveness, it is important to achieve conceptual equivalence. This is key to ensuring that target text readers are familiar with the notions discussed (Brewster, Tregaskis, Hegewisch and Mayne, 2003). 


\subsection{Supervisors}

The analysis conducted on the dataset made up of Italian documents containing the word quadri and their English translation reveals that the recourse to "supervisors" to render the Italian concept investigated in this paper is relatively frequent. Looking at the definition of a supervisor, the Oxford English Dictionary (OED) specifies that she/he is "a person who supervises a person or an activity" (Oxford English Dictionary, 2019). In the same vein, Merriam-Webster's definition of a supervisor is as follows: "one that supervises; especially: an administrative officer in charge of a business, government, or school unit or operation" (Merriam-Webster, 2019). It is a fact that employees holding managerial positions have supervisory functions. However, overseeing is required to all the management, so this task is not the preserve of quadri. Both top managers, middle managers and sometimes even white collar workers are required to superintend other people's work, thus making this translation too a generic one to convey the meaning of quadri. Furthermore, supervision is only one of the tasks required of them. This holds true if one takes into account the definition of quadri provided by Italy's National Institute of Statistics (ISTAT), where it is specified that a quadro is "person who, in the technical and administrative field, undertakes, with different degrees of responsibility, discretionary and independent powers, management and/or co-ordination functions in a service or office" (ISTAT, 1995). The problem faced here is twofold. On the one hand, the work of quadri is not limited to supervising other employees. On the other hand, supervision is a task that is common to a number of profiles occupying managerial positions. Consequently, using "supervisors" to render quadri might perplex readers who are not familiar with the system of classification related to employment status in Italy.

\subsection{Senior Managers}

When looking at the language employed to render the Italian notion of quadri in English, "senior managers" is another widely used expression. Like some of the terminology examined in this paper to translate the concept at hand into English - e.g. "managers" "senior managers" might be taken to include different roles, depending on the system of employment classification in place. However, one might note that resorting to this wording might instill confusion in the reader, as doubts might arise as to whether quadri are top managers or not. This point is further reinforced if one looks at the definition of "senior managers" or "senior management" provided by the dictionary, as they are often used synonymously with "top managers" or "top management". It is stated that senior managers are "managers at the highest level of a company or organization, considered as a group" (Cambridge Dictionary, 2019, emphasis added). More specifically, "to be a top-manager let's use the word senior - means to have everyone else in the organization reporting to you, which means to have formal responsibilities for the activities of the entire place" (Mintzberg, 2009 , p. 109). Resorting to this terminology to refer to quadri is therefore problematic because they are not the highest-rated employees in an organization, especially if the Italian classification system is considered. In Italy, the employee holding top-level positions is known as dirigente, namely "a person who has a role characterized by a high degree of expertise, independence and decision-making powers, and who undertakes his job in order to promote, co-ordinate and manage the achievement of the goals of the enterprise or body" 
(Tiraboschi, 2010, p. 10).

\section{Conclusions}

This paper examined the struggle resulting from translating job-level terminology from Italian into English, focusing on the notion of quadri. This concept is problematic because is peculiar to Italy's system of employee classification, thus posing challenges when attempting to render this notion in English. The analysis on the dataset scrutinized, which consisted of a number of corporate reports originally produced in Italian and subsequently translated into English, revealed that different terms had been used to convey the meaning of the notion under scrutiny. The most widespread terminology adopted in English to refer to the Italian quadri is "middle-managers". Ideally, and especially for the purpose of comparison, this wording can be a suitable rendering to refer to quadri, as "middle managers" generically denote the job level between top management and white-collar employees, which is exactly the case of quadri. The only issue that might stem from resorting to this expression is that, looking at the Italian context, middle managers can include both managers and professionals, with the latter being quadri in the strict sense and performing different tasks from the former. Consequently, "professionals" is the most adequate expression to transpose the concept at issue into English. This is true also when looking at the other options put in place by translators to navigate this linguistic issue.

Considering the dataset compiled for this analysis, "managers" is the second most-widely used expression to render quadri in English. As seen, opting for this word is problematic for two main reasons. Firstly, "managers" is an overarching word for a wide range of positions. While it is true that making use of superordinates is a diffused translation strategy, employing "managers" to convey the meaning of quadri might perplex the international reader, as this lack of specificity does not help one to clearly understand to which job level reference is made. Secondly, and when specifically looking at Italy's employee classification system, it was stressed that "managers" could also indicate a subcategory of the middle management. Assuming this, we saw that managers are not the same as professionals, which is precisely the terminology used to translate quadri into English. Consequently, "managers" can be seen as a red herring when used to render the Italian notion currently under examination. Equally misleading is the choice to rest on "supervisors" to transpose the meaning of quadri into English. The problem with this rendering is that overseeing other people's work is not the preserve of quadri, as both top management and middle management perform supervisory roles. Thus the attempt to focus on one's responsibilities - supervision in this case - to distinguish between different job levels might give rise to misinterpretations, resulting in confusion among readers who are not familiar with Italy's classification of employment status.

Interpretation problems might also arise if quadri is rendered as "senior managers" in English. In this case, the terminology adopted in English can be questioned because it is usually taken to denote the Italian dirigenti, viz. top or executive management, leading to uncertainty as to whether quadri refers to middle or top managers.

To conclude, the analysis just provided is illustrative of one of the most common issues in TS, 
namely the rendering of context-bound concepts from one language into another. Compounding the picture in the case of quadri is the fact that, depending on their job levels, staff members are covered by different legal and contractual positions, so clarity is needed when referring to them in order to apply relevant legislation. This research bears relevance in that it points out the translation problems multinationals should be aware of when transposing terminology identifying managerial positions into different languages and systems.

One aspect that can be examined in future research, and that falls outside the scope of this paper, is to investigate whether the linguistic issues highlighted have also produced consequences at the time of awarding bonuses and setting job responsibilities, which frequently depend on seniority.

\section{References}

Bargiela-Chiappini, F. (2001). Management, Culture and Discourse in International Business. In M. Stroinska (Ed.), Relative Points of View: Linguistic Representation of Culture (pp. 143-160). New York: Berghahn Books.

Bargiela-Chiappini, F., \& Harris, J. S. (1997). Managing Language. The Discourse of Corporate Meetings. Amsterdam: John Benjamins Publishing. https://doi.org/10.1075/pbns.44

Barsoux, J. L., \& Lawrence, P. (2006). French Management. Elitism in Action. Abingdon: Taylor and Francis.

Borsa, I. (2019). Homepage. Retrieved May 13, 2019, from https://www.borsaitaliana.it/borsa/azioni/listino-a-z.html?initial=A

Brewster, C., Tregaskis, O., Hegewisch, A., \& Mayne, L. (2003). Comparative Research in Human Resource Management: A Review and an Example. In M. Poole (Ed.), Human Resource Management, Critical Perspectives on Business and Management, Comparative, International and Strategic Human Resource Management (Volume II, pp. 267-290). London: Routledge.

Byrne, J. (2012). Scientific and Technical Translation Explained: A Nuts and Bolts Guide for Beginners. Translation Practices Explained. London: Routledge.

Cambridge Dictionary. (2019). Senior Management. Retrieved May 7, 2019, from https://dictionary.cambridge.org/it/dizionario/inglese/senior-management

Cullen, J. B., \& Parboteeath, K. P. (2014). Multinational Management. A Strategic Approach (6th ed.). Mason: South Western Cengage Learning.

Erkens, M. H. R. (2016). Disclosure Behaviour of European Firms around the Adoption of IFRS. Wiesbaden: Springer Gabler. https://doi.org/10.1007/978-3-658-13441-9

Fairbrother, L. (2018). The Management of Everyday English Interactions in the Japanese Branches of European Multinationals. In T. Sherman, \& J. Nekvapil (Eds.), English in Business and Commerce: Interactions and Policies - English in Europe (Vol. 6, pp. 149-171). Boston: De Gruyter-Mouton. https://doi.org/10.1515/9781501506833-007

Hyman, R. (2005). Words and Things: The Problem of Particularistic Universalism. In J. C. Barbier, \& M. T. Letablier (Eds.), Comparaisons internationals des politiques sociales, enjeux épistémologiques et méthodologiques/Cross-national comparison of social policies: 
Epistemological and methodological issues (pp. 191-208). Brussels: PIER Peter Lang ISTAT. (2019). Definition of Senior Management. Quoted in Tiraboschi, M. (2010). The Position and Function of Executive Staff Members in Italian Labour Law. In M. Weiss, A. M. Seifert, G. Kronisch, J. Gschwinder, \& W. Bromwich (Eds.), Arbeitsrecht für Führungskräfte in ausgewählten Rechtsordnungen - Labour law of executive staff in selected countries (pp. 2-47). Milano: Nomos.

Khuddro, A. (2016). Translating Business English into Arabic - Learning through Practice Series. Footscray: AIAC.

Lorrimar, N. (2010). A Bilingual Encyclopaedia. In F. Bornouis, J. Duval-Hamel, S. Rousillon, \& J. L. Scaringella (Eds.), Handbook of Top Management Teams (pp. 434-439). New York: Palgrave Mc-Millan.

Manzella, P. (2017). Multilingual translation of industrial relations practices in official EU documents: the case of Italy's Cassa Integrazione Guadagni. Perspectives. Studies in Translation Theory and Practice, 26(3), 344-356. https://doi.org/10.1080/0907676X.2017.1347190

Merriam, W. (2019). Supervisor. Retrieved February 12, 2019, from https://www.merriam-webster.com/dictionary/supervisor

Mintzberg, H. (2009). Managing. San Francisco: BK.

Oxford Dictionary. (2019). Supervisor. Retrieved January 20, 2019, from https://www.lexico.com/en/definition/supervisor

Pierini, H., \& Tosi, G. (2006). Dai racconti dei top manager - Informazioni riservate. Come fare carriera dal primo lavoro ai vertici aziendali. Milano: Edizioni AlphaTest.

Preece, D., Steven, G., \& Steven, V. (1999). Work Change and Competition - Managing for Bass. New York: Routledge.

Storey, J., Edwards, P., \& Sisson K. (1999). Managers in the Making, Careers, Development and Control in Corporate Britain and Japan. London: Sage.

Tietze, S. (2008). International Management and Language - Routledge Studies in International Business and the World Economy. Abingdon: Routledge.

Tiraboschi, M. (2010). The Position and Function of Executive Staff Members in Italian Labour Law. In M. Weiss, A. Michele, Seifert, G. Kronisch, J. Gschwinder, \& W. Bromwich (Eds.), Arbeitsrecht für Führungskräfte in ausgewählten Rechtsordnungen - Labour law of executive staff in selected countries (pp. 2-47). Milano: Nomos.

\section{Copyrights}

Copyright for this article is retained by the author(s), with first publication rights granted to the journal.

This is an open-access article distributed under the terms and conditions of the Creative Commons Attribution license (http://creativecommons.org/licenses/by/4.0/) 